\title{
WAVE EQUATION WITH $p(x, t)$-LAPLACIAN AND DAMPING TERM: EXISTENCE AND BLOW-UP
}

\author{
STANiSLAV ANTONTSEV
}

Abstract. In this work, we consider the Dirichlet problem for equation

$$
u_{t t}=\operatorname{div}\left(a(x, t)|\nabla u|^{p(x, t)-2} \nabla u\right)+\alpha \Delta u_{t}+b(x, t)|u|^{\sigma(x, t)-2} u+f(x, t) .
$$

Under suitable conditions on the functions $a, b, f, p, \sigma$ the local, global and blow up solutions have been discussed.

Mathematics subject classification (2010): 35B40, 35L70, 35L45.

Keywords and phrases: nonlinear wave equations, energy estimates, global existence, blow up, nonstandard growth conditions.

\section{REFERENCES}

[1] S. Antontsev, Wave equation with $p(x, t)$ - Laplacian and damping term: Existence and blow-up, in Proceedings of the International Conference "Modern Problems of Applied Mathematics and Mechanics: Theory, Experiment and Applications" devoted to the 90th anniversary of Prof. N.N Yanenko, Novosibirsk, Russia, May 30-June 4, 2011.

[2] S. Antontsev, Wave equation with $p(x, t)$-Laplacian and damping term: Existence and blow-up, in Abstracts, Nonlinear Models in Partial Differential Equations, An international congress on occasion of J.I. Diaz's 60th birthday, Toledo, Spain, June 14-17, 2011, p. 8.

[3] S. Antontsev, Wave equation with $p(x, t)$-Laplacian and damping term: Blow-up of solutions, C. R. Mecanique, (2011, in press).

[4] S. Antontsev, M. Chipot, And Y. Xie, Uniqueness results for equations of the $p(x)$-Laplacian type, Adv. Math. Sci. Appl., 17 (2007), 287-304.

[5] S. N. Antontsev, J. I. Díaz, And S. Shmarev, Energy Methods for Free Boundary Problems: Applications to Non-linear PDEs and Fluid Mechanics, Bikhäuser, Boston, 2002. Progress in Nonlinear Differential Equations and Their Applications, Vol. 48.

[6] S. N. Antontsev And J. F. Rodrigues, On stationary thermo-rheological viscous flows, Ann. Univ. Ferrara, Sez.,VII. Sci. Mat., 52 (2006), 19-36.

[7] S. N. Antontsev AND S. I. Shmarev, Elliptic equations and systems with nonstandard growth conditions: existence, uniqueness and localization properties of solutions, Journal Nonlinear Analysis, 65 (2006), 722-755.

[8] S. N. AntontSeV AND S. I. Shmarev, Elliptic equations with anisotropic nonlinearity and nonstandard growth conditions, Elsevier, 2006. Handbook of Differential Equations. Stationary Partial Differential Equations, Elsevier, Vol. 3, Chapter 1, 1-100.

[9] S. N. Antontsev And S. I. Shmarev, Parabolic equations with anisotropic nonstandard growth conditions, in Internat. Ser. Numer. Math. 154, Birkhäuser, Verlag Basel/Switzerland, 2006, 33-44.

[10] S. N. ANTONTSEV AND S. I. Shmarev, Extinction of solutions of parabolic equations with variable anisotropic nonlinearities, Proceedings of the Steklov Institute of Mathematics, Moscow, Russia, 268 (2008), 2289-2301.

[11] S. N. Antontsev And S. I. Shmarev, Anisotropic parabolic equations with variable nonlinearity, Publ. Sec. Mat. Univ. Autònoma Barcelona, (2009), 355-399.

[12] S. N. ANTONTSEV AND S. I. SHMAREV, Localization of solutions of anisotropic parabolic equations, Nonlinear Anal., 71 (2009), e725-e737. 
[13] S. N. Antontsev And S. I. Shmarev, Blow-up of solutions to parabolic equations with nonstandard growth conditions, Journal of Computational and Applied Mathematics, 234 (2010), 26332645.

[14] G. Autuori, P. Pucci, AND M. C. SAlvatori, Asymptotic stability for anisotropic Kirchhoff systems, J. Math. Anal. Appl., 352 (2009), 149-165.

[15] G. AUtUORI, P. PUCCI, AND M. C. SAlVATORI, Global nonexistence for nonlinear Kirchhoff systems, Arch. Rational Mech. Anal., 196 (2011), 489-516.

[16] J. Clements, Existence theorems for a quasilinear evolution equation, SIAM J. Appl. Math., 26 (1974), 745-752.

[17] L. Diening, P. Harjulehto, P. Hasto, And M. RÚŽIČKa, Lebesgue and Sobolev Spaces with Variable Exponents, Springer, Berlin, 2011. Series: Lecture Notes in Mathematics, Vol. 2017,1st Edition.

[18] M. DReHER, The wave equation for the p-Laplacian, Hokkaido Math. J., 36 (2007), 21-52.

[19] V. A. Galaktionov AND S. I. Pohozaev, Blow-up and critical exponents for nonlinear hyperbolic equations, Nonlinear Analysis, 53 (2003), 453-466.

[20] H. GAO AND T. F. MA, Global solutions for a nonlinear wave equation with p-Laplacian operator, EJQTDE., (1999), 1-13.

[21] V. Georgiev AND G. Todorova, Existence of a solution of the wave equation with nonlinear damping and source terms, J. Differential Equations, 109 (1994), 295-308.

[22] J. HAEHnle AND A. PRohl, Approximation of nonlinear wave equations with nonstandard anisotropic growth conditions, Math. Comp., 79 (2010), 189-208.

[23] M. JAZAR AND R. KIWAN, Blow-up results for some second-order hyperbolic inequalities with a nonlinear term with respect to the velocity, J. Math. Anal. Appl., 327 (2007), 12-22.

[24] M. JAZAR AND R. KIWAN, Blow-up of a non-local semilinear parabolic equation with Neumann boundary conditions, Ann. Inst. H. Poincaré Anal. Non Linéaire, 25 (2008), 215-218.

[25] T. KATO, Blow up of solutions of some nonlinear hyperbolic equations, Manuscripta Math., 28 (1980), 235-268.

[26] H. LEVINE AND G. TODOROVA, Blow-up of solutions of the cauchy problem for a wave equations with nonlinear damping and source terms and positive initial energy, in Proceedings of the American Mathematical Society, 129 (2000), 793-805.

[27] J.-L. Lions, Quelques méthodes de résolution des problèmes aux limites non linéaires, Dunod, 1969.

[28] S. A. MESSAOUdi, Blow up in a nonlinearly damped wave equation, Math. Nachr., 231 (2001), 105111.

[29] S. A. MESSAOUdi, Blow up in the Cauchy problem for a nonlinearly damped wave equation, Commun. Appl. Anal., 7 (2003), 379-386.

[30] S. A. MessaOUd, On the decay of solutions for a class of quasilinear hyperbolic equations with non -linear damping and source terms, Mathematical Methods in the Applied Sciences, 28 (2005), 1819-1828.

[31] S. A. Mess aOudi AND B. SAID Houari, Global non-existence of solutions of a class of wave equations with non-linear damping and source terms, Math. Methods Appl. Sci., 27 (2004), 16871696.

[32] C. MU, R. ZENG, AND B. CHEN, Blow-up phenomena for a doubly degenerate equation with positive initial energy, Nonlinear Anal., 72 (2010), 782-793.

[33] M. NAKAO AND Y. ZHIJIAN, Global attractors for some quasi-linear wave equations with a strong dissipation, Adv. Math. Sci. Appl., 17 (2007), 89-105.

[34] J. P. PInASCO, Blow-up for parabolic and hyperbolic problems with variable exponents, Nonlinear Anal., 71 (2009), 1094-1099.

[35] K. Rajagopal AND M. RÚŽIČKa, Mathematical modelling of electro-rheological fluids, Cont. Mech. Therm., 13 (2001), 59-78.

[36] M. RÚŽIČKA, Electrorheological fluids: modeling and mathematical theory, Springer, Berlin, 2000. Lecture Notes in Mathematics, 1748.

[37] A. A. Samarskit, V. A. Galaktionov, S. P. Kurdyumov, and A. P. Mikhailov, Blow-up in quasilinear parabolic equations, Walter de Gruyter \& Co., Berlin, 1995. Translated from the 1987 Russian original by Michael Grinfeld and revised by the authors.

[38] S. G. SAMKo, Density $C_{0}^{\infty}\left(\mathbb{R}^{n}\right)$ in the generalized Sobolev spaces $W^{m, p(x)}\left(\mathbb{R}^{n}\right)$, Dokl. Akad. Nauk, 369 (1999), 451-454. 
[39] J. Simon, Compact sets in the space $l^{p}(0, t ; b)$, Ann. Mat. Pura Appl., IV. Ser., 146 (1952), $65-96$.

[40] G. TOdorova AND E. Vitillario, Blow-up for nonlinear dissipative wave equations in $\mathbb{R}^{n}, \mathrm{~J}$. Math. Anal. Appl., (2005), 242-257.

[41] Z. Wilstein, Global well-posedness for a nonlinear wave equation with $p$ Laplacian damping, Dissertation, University of Nebraska-Lincoln, downloaable at :http://digitalcommons.unl.edu/mathstudent/24, (2011), 1-116.

[42] Z. YANG, Cauchy problem for quasi-linear wave equations with viscous damping, J. Math. Anal. Appl., 320 (2006), 859-881.

[43] Z. YANG AND G. CHEN, Global existence of solutions for quasi-linear wave equations with viscous damping, J. Math. Anal. Appl., 285 (2003), 604-618.

[44] Y. ZHIJIAN, Existence and asymptotic behaviour of solutions for a class of quasi-linear evolution equations with non-linear damping and source terms, Mathematical Methods in the Applied Sciences, 25 (2002), 795-814.

[45] Y. ZhiJiAn, Global existence, asymptotic behavior and blowup of solutions for a class of nonlinear wave equations with dissipative term, J. Differential Equations, 187 (2003), 520-540.

[46] Y. ZHIJIAN, Initial boundary value problem for a class of non-linear strongly damped wave equations, Math. Methods Appl. Sci., 26 (2003), 1047-1066.

[47] Y. ZHIJIAN, Cauchy problem for a class of nonlinear dispersive wave equations arising in elastoplastic flow, J. Math. Anal. Appl., 313 (2006), 197-217.

[48] V. V. Zhikov, On the density of smooth functions in Sobolev-Orlich spaces, Zap. Nauchn. Sem. S.-Peterburg. Otdel. Mat. Inst. Steklov. (POMI), 310 (2004), 1-14. 